\title{
PKM PENERAPAN MAXIMUM POWER POINT TRACKER (MPPT) PADA SISTEM POMPA AIR SOLAR PHOTO VOLTAIC (SPV) UNTUK RW8 KELURAHAN ROWOSARI KOTA SEMARANG
}

\author{
Titik NURHARYATI ${ }^{1}$, Bambang SUDARMANTO², Agus MARGIANTONO3 \\ Jurusan Teknik Elektro Fakultas Teknik Universitas Semarang \\ Email: titiknur@usm.ac.id
}

\begin{abstract}
Rowosari Urban Village is a village located in Tembalang District, Semarang City. The Rowosari Urban Village has an area of 719,577 Ha at an altitude of $47 \mathrm{~m}$ above sea level with an average rainfall of $2,000 \mathrm{~mm} /$ year, an average temperature of $300 \mathrm{C}$. According to Purwoko, SH, Head of Rowosari Village, when met by the Community Partnership Program Team (PKM) in the Rowosari Kelurahan office, problems in Rowosari Kelurahan, especially in RW 8, one of which was the high electricity bill, especially for public facilities such as prayer rooms and low human resources (HR) ), therefore the purpose of this PKM is to reduce electricity bills and increase the human resources of the Rowosari Kelurahan, Tembalang District, Semarang City through training in the Implementation of the Maximum Power Point Tracker (MPPT) in the Water Pump System. To overcome the problems of partners especially the priority that must be addressed, the University of Semarang PKM team used a method with 3 stages of activities namely HR Enhancement through Solar Photo Voltaic (SPV) assembly training, Assistance in Solar Photo Voltaic (SPV) assembly, and Installation of electric pumps that produced from Solar Photo Voltaic (SPV).

The results of this PKM activity are water pumps in wells in the RT.02 / RW mosque. 8 Kelurahan Rowosari has used a Solar Photo Voltaic Water Pump (SPV).

Keywords: Solar Photovolic (SPV), low human resources (HR), partner problems

\section{ABSTRACT}

Kelurahan Rowosari merupakan kelurahan yang terletak di Kecamatan Tembalang Kota Semarang. Wilayah Kelurahan Rowosari memiliki luas $719.577 \mathrm{Ha}$ yang berada pada ketinggian $47 \mathrm{~m}$ dpl dengan curah hujan rata-rata $2.000 \mathrm{~mm} /$ tahun, keadaan suhu rata-rata $30^{\circ} \mathrm{C}$. Menurut Purwoko, SH, Lurah Rowosari, saat di temui Tim Program Kemitraan Masyarakat (PKM) di kantor Kelurahan Rowosari, permasalahan di Kelurahan Rowosari khususnya di RW 8 salah satunya adalah tingginya tagihan listrik terutama untuk fasilitas umum sperti mushola dan rendahnya sumber daya manusia (SDM), oleh karena itu tujuan dari PKM ini adalah menurunkan tagihan listrik dan meningkatkan SDM masyarakat Kelurahan Rowosari Kecamatan Tembalang Kota Semarang melalui pelatihan Penerapan Maximum Power Point Tracker (MPPT) Pada Sistem Pompa Air. Untuk mengatasi permasalahan mitra terutama yang menjadi prioritas yang harus ditangani, maka tim PKM Universitas Semarang menggunakan metode dengan 3 tahap kegiatan yaitu Peningkatan SDM melalui pelatihan perakitan Solar Photo Voltaic (SPV), Pendampingan perakitan Solar Photo Voltaic (SPV), dan Pemasangan pompa listrik yang dihasilkan dari Solar Photo Voltaic (SPV).

Hasil kegiatan PKM ini adalah pompa air pada sumur di mushola RT.02/RW. 8 Kelurahan Rowosari telah menggunakan Pompa Air Solar Photo Voltaic (SPV).
\end{abstract}

Kata Kunci: Solar Photovolic (SPV), sumber daya manusia (SDM) rendah, permasalahan mitra, 


\section{Pendahuluan}

\subsection{Analisis Situasi}

Kelurahan Rowosari merupakan kelurahan yang terletak di Kecamatan Tembalang Kota Semarang. Batas administratif Kelurahan Rowosari adalah sebagai berikut: Batas Utara berbatasan dengan desa. Kebunbatur Kab. Demak, Batas Timur berbatasan dengan desa. Banyumeneng Kab. Demak, Batas Selatan berbatasan dengan desa Kalikayen Kab. Semarang, Batas Barat berbatasan dengan Kel. Meteseh Kec. Tembalang. Kelurahan Rowosari 44 Rukun Tetangga (RT) dan 9 Rukun Warga (RW).

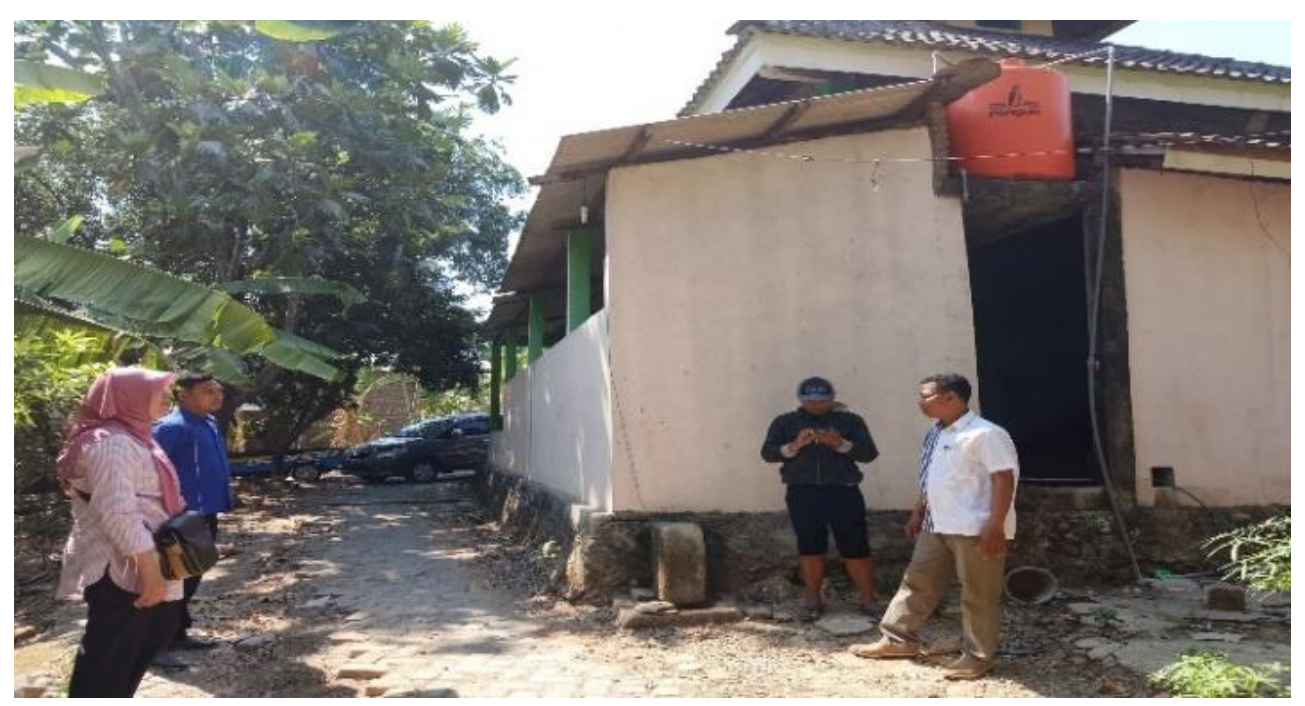

Gambar 1.Kunjungan Tim Ke Kelurahan Rowosari

Wilayah Kelurahan Rowosari memiliki luas $719.577 \mathrm{Ha}$ yang berada pada ketinggian $47 \mathrm{~m}$ dpl dengan curah hujan rata-rata $2.000 \mathrm{~mm} /$ tahun, keadaan suhu rata-rata $30^{\circ} \mathrm{C}$. Jumlah penduduk menurut usia di kelurahan Rowosari seperti terlihat pada tabel 1. Menurut Purwoko, SH, Lurah Rowosari, saat di temui Tim PKM di kantor Kelurahan Rowosari (Gambar 1), terdapat beberapa permasalahan di kelurahanya antara lain fasilitas penerangan listrik yang sering terganggu, tingginya tagihan listrik khususnya untuk fasilitas umum seperti mushola dan rendahnya sumber daya manusia (SDM). Dari tabel 2, terdapat 2.123 penduduk di kelurahan Rowosari berprofesi karyawan. Berdasarkan wawancara yang telah dilakukan tim PKM dengan ketua RW 8 Bapak Alimin, sebagian besar merupakan karyawan atau lebih tepatnya buruh pabrik di PT Bitratex (pabrik Tekstil), sedang 1.466 yang berprofesi tukang bangunan atau lebih tepatnya buruh bangunan. Informasi dari Bapak Alimin (Gambar 1), dari kedua data jenis pekerjaaan di kelurahan Rowosari tersebut kurang lebih $50 \%$ berasal dari RW8. Dari pengamatan TIM PKM di RW.8, walaupun pembangunan infrastruktur terus digalakan, dibeberapa tempat masih terdapat jalan tanah yang selalu bermasalah saat musim hujan, rumah-rumah sederhana, fasilitas sangat terbatas serta Sumber Daya Manusia (SDM) rendah. 


\begin{tabular}{lc}
\hline $\begin{array}{c}\text { Jumlah Penduduk Menurut } \\
\text { Usia }\end{array}$ & Jml \\
\hline $\begin{array}{c}\text { a. Kelompok Pendidikan } \\
\text { 1). } 04-06 \text { tahun }\end{array}$ & 672 \\
2). $07-12$ tahun & 1.022 \\
3). 13 - 15 tahun & 1.143 \\
4). 16 - 19 tahun & 1.197 \\
b. Kelompok Tenaga Kerja & \\
1). 20 - 26 tahun & 1.203 \\
2). 27 - 40 tahun & 3.207 \\
3). 41 - 60 tahun & 3.034 \\
c. Kelompok Usia Lanjut & \\
61 tahun - keatas & 341 \\
\hline
\end{tabular}

(Sumber: Monografi Kelurahan Rowosari, Oktober 2018)

\subsection{PERMASALAHAN MITRA}

Pengamatan yang telah dilakukan tim PKM menunjukan ada beberapa permasalahan di Kelurahan Rowosari khususnya di RW 8 adalah :

- Tagihan listrik masih dirasa cukup tinggi terutama untuk fasilitas umum seperti mushola.

- Rendahnya Sumber Daya Manusia (SDM)

\section{METODE PELAKSANAAN}

Untuk mengatasi permasalahan mitra, maka tim PKM memberikan pelatihan Penerapan Maximum Power Point Tracker (MPPT) Pada Sistem Pompa Air Solar Photo Voltaic (SPV) yang dilaksanakan dalam 5 tahap yaitu : Pelatihan Perakitan Solar Photo Voltaic (SPV, Pendampingan Perakitan Solar Photo Voltaic (SPV),Pemasangan pompa berbahan bakar listrik yang dihasilkan dari Solar Photo Voltaic (SPV) dan Monitoring Dan Evaluasi. Gambaran umum pelatihan ini sebagai berikut ;
a) Pelaksana: Tim PKM
b) Peserta : Karang Taruna Kelurahan Rowosari khususnya di RW 8.
c) Intruktur : Tim PKM Universitas Semarang.
d) Lokasi : RW 8 Kelurahan Rowosari.

Kegiatan Monitoring Dan Evaluasi bertujuan untuk memonitor kegiatan selama pelatihan, setelah selesai pelatihan dan pernerapan pompa berbahan bakar listrik yang dihasilkan dari Solar Photo Voltaic (SPV). Disamping itu kegiatan ini juga mengidentfikasi masalah atau hambatan yang ada pada saat penerapan dan penggunaan alat yang baru selama 6 bulan setelah penerapan. Jika dalam waktu 6 bulan masih di temukan masalah dilapangan, pengabdian kepada masyarakat akan tetap dilanjutkan dengan dana dari internal Universitas Semarang, disamping itu dengan meningkatnya SDM di RW 8 Kelurahan Rowosari setelah mengikuti pelatihan pemasangan pompa berbahan bakar listrik yang dihasilkan dari Solar Photo Voltaic (SPV) akan lebih menjamin keberlanjutan PKM ini. Diharapkan dengan keberhasilan PKM ini RW dan kelurahan lain dapat tertarik untuk melakukan dan menerapkan peralatan serupa pada sumur miliknya. Secara umum gambaran PKM ini terlihat pada gambar 4. 


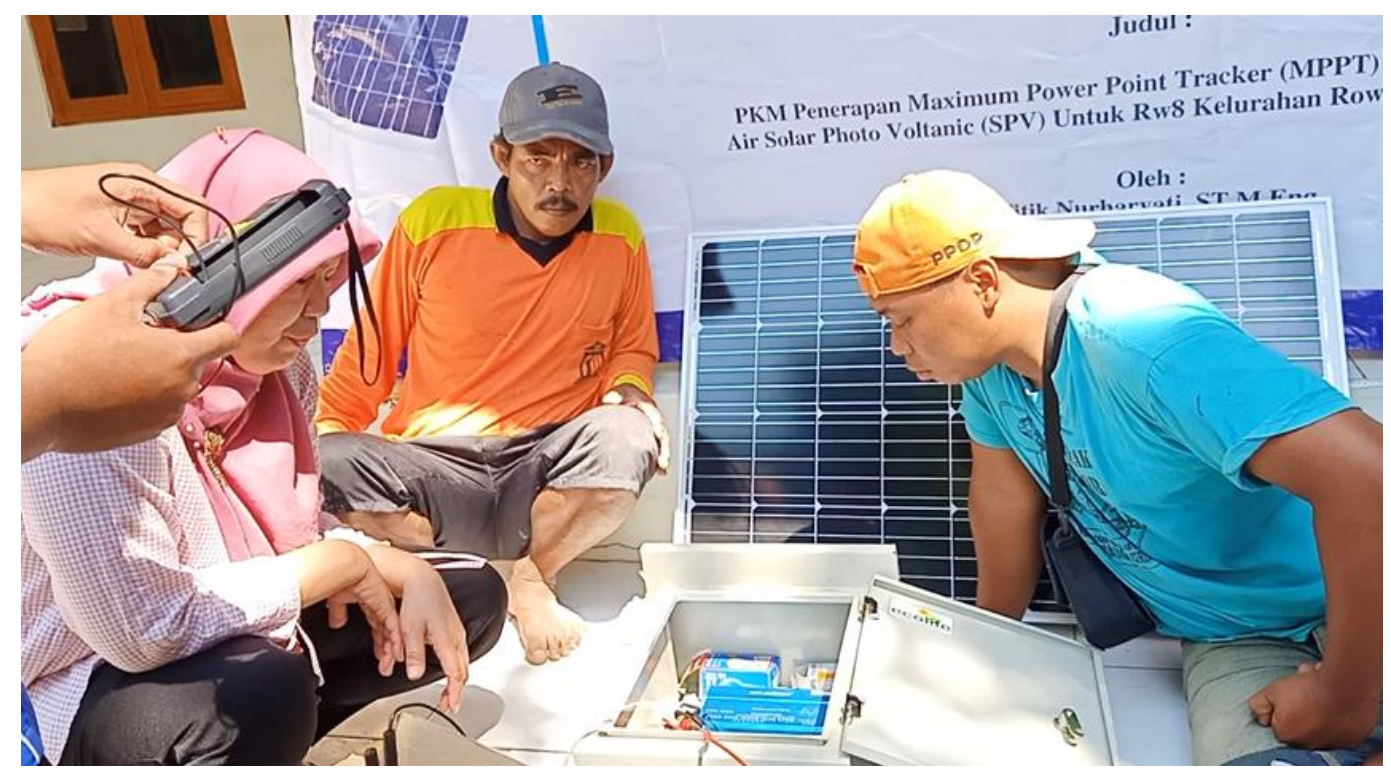

Gambar 3. Pelaksanaan Pelatihan Penerapan

Maximum Power Point Tracker (MPPT)

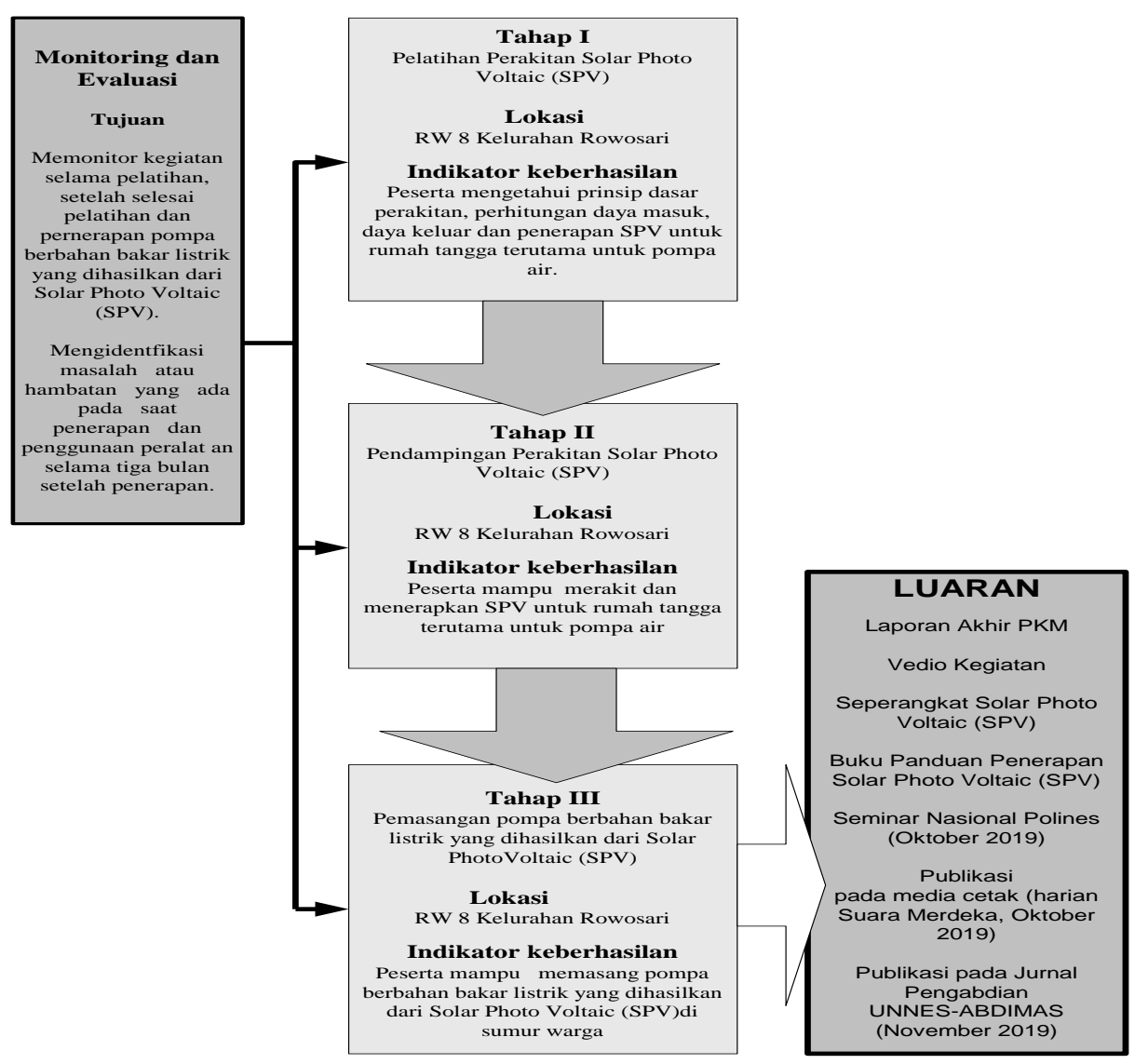

Gambar 4..Diagram Alir Penahapan PKM 


\section{Hasil dan Pembahasan}

Sebelum melakukan pelatihan tim PKM melakukan pembuatan modul. Modul ini diperlukan agar mitra dapat dengan mudah mempelajari Penerapan Maximum Power Point Tracker (MPPT). Modul ini berupa panduan praktis cara-cara menerapan Maximum Power Point Tracker (MPPT). Melihat dari hasil pelatihan, hampir semua peserta sudah mampu menerapan Maximum Power Point Tracker (MPPT). Peserta sangat antusias mengikuti pelatihan karena pelatihan ini merupakan kebutuhan bagi masyarakat RT.02 RW8 Kelurahan Rowosari Kota Semarang. Secara umum beberapa hal yang sudah dicapai setelah pelahan ini ditunjukan pada Tabel 2.

Tabel 2. Capaian Pelaksanaan PKM

\begin{tabular}{|c|c|c|}
\hline SEBELUM PELATIHAN & SETELAH PELATIHAN & LUARAN \\
\hline $\begin{array}{l}\text { Masyarakat Rowosari Belum mengetahui } \\
\text { energy listrik dapat di bangkitkan dari } \\
\text { cahaya Matahari melalui panel Surya }\end{array}$ & $\begin{array}{l}\text { Masyarakat Rowosari sudah } \\
\text { mengetahui energy listrik dapat di } \\
\text { bangkitkan dari cahaya Matahari } \\
\text { melalui panel Surya }\end{array}$ & $\begin{array}{l}\text { Modul Pelatihan } \\
\text { Panel Surya }\end{array}$ \\
\hline $\begin{array}{l}\text { Masyarakat Rowosari Belum Bisa } \\
\text { merakit perangkat panel surya untuk } \\
\text { membangkitkan energy listrik }\end{array}$ & $\begin{array}{l}\text { Masyarakat Rowosari sudah Bisa } \\
\text { merakit perangkat panel surya untuk } \\
\text { membangkitkan energy listrik }\end{array}$ & $\begin{array}{l}\text { Modul Pelatihan } \\
\text { Panel Surya }\end{array}$ \\
\hline $\begin{array}{l}\text { Masyarakat Rowosari Belum mengetahui } \\
\text { kegunaan komponen-komponen panel } \\
\text { surya seperti Solar Controller dan } \\
\text { inverter. }\end{array}$ & $\begin{array}{l}\text { Masyarakat Rowosari sudah } \\
\text { mengetahui kegunaan komponen- } \\
\text { komponen panel surya seperti Solar } \\
\text { Controller dan inverter. }\end{array}$ & $\begin{array}{l}\text { Solar Controller } \\
\text { inverter }\end{array}$ \\
\hline $\begin{array}{l}\text { Belum ada pompa air bertenaga listrik } \\
\text { yang dihasilkan dari panel surya }\end{array}$ & $\begin{array}{l}\text { ada pompa air bertenaga listrik yang } \\
\text { dihasilkan dari panel surya }\end{array}$ & $\begin{array}{l}\text { Perangkat Panel } \\
\text { Surya }\end{array}$ \\
\hline
\end{tabular}

(sumber: data primer pelaksanaan PKM, 2019)

Indek kepuasan pelaksanaan pelatihan Penerapan Maximum Power Point Tracker (MPPT), bagi masyarakat RT.02 RW8 Kelurahan Rowosari Kecamatan Tembalang Kota Semarang menunjukan peserta menyatakan setuju dan puas dengan adanya pelatihan Penerapan Maximum Power Point Tracker (MPPT). Hal ini terlihat dari indek kepuasan peserta sebesar 3,5 dalam skala 5. 
Tabel 3. Kepuasan Pelaksanaan Pelatihan Solar Photo Voltaic (SPV)

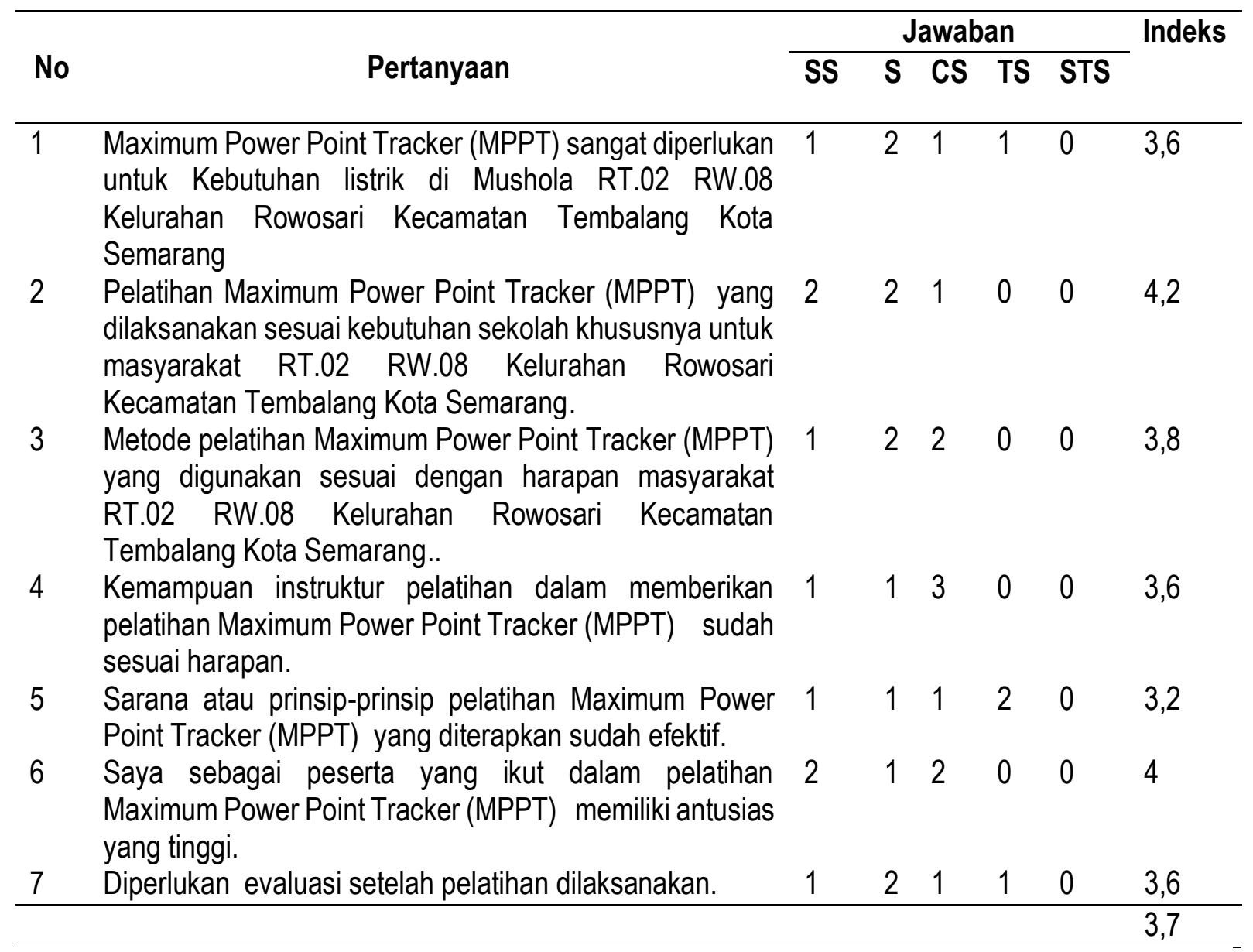

(sumber: data primer pelaksanaan PKM)

Setelah MPPT terpasang di mushola RT.02/RW.08 dilakukan pengukuran tegangan yang keluar dari panel surya sebesar $12 \mathrm{~V} \mathrm{DC}$ dan tegangan yang keluar dari inverter sebesar $220 \mathrm{~V}$ AC sehingga tegangan telah sesuai untuk mensuplai listrik di mushola khususnya untuk pompa air dan langsung dilakukan serah terima peralatan seperti terlihat pada gambar 

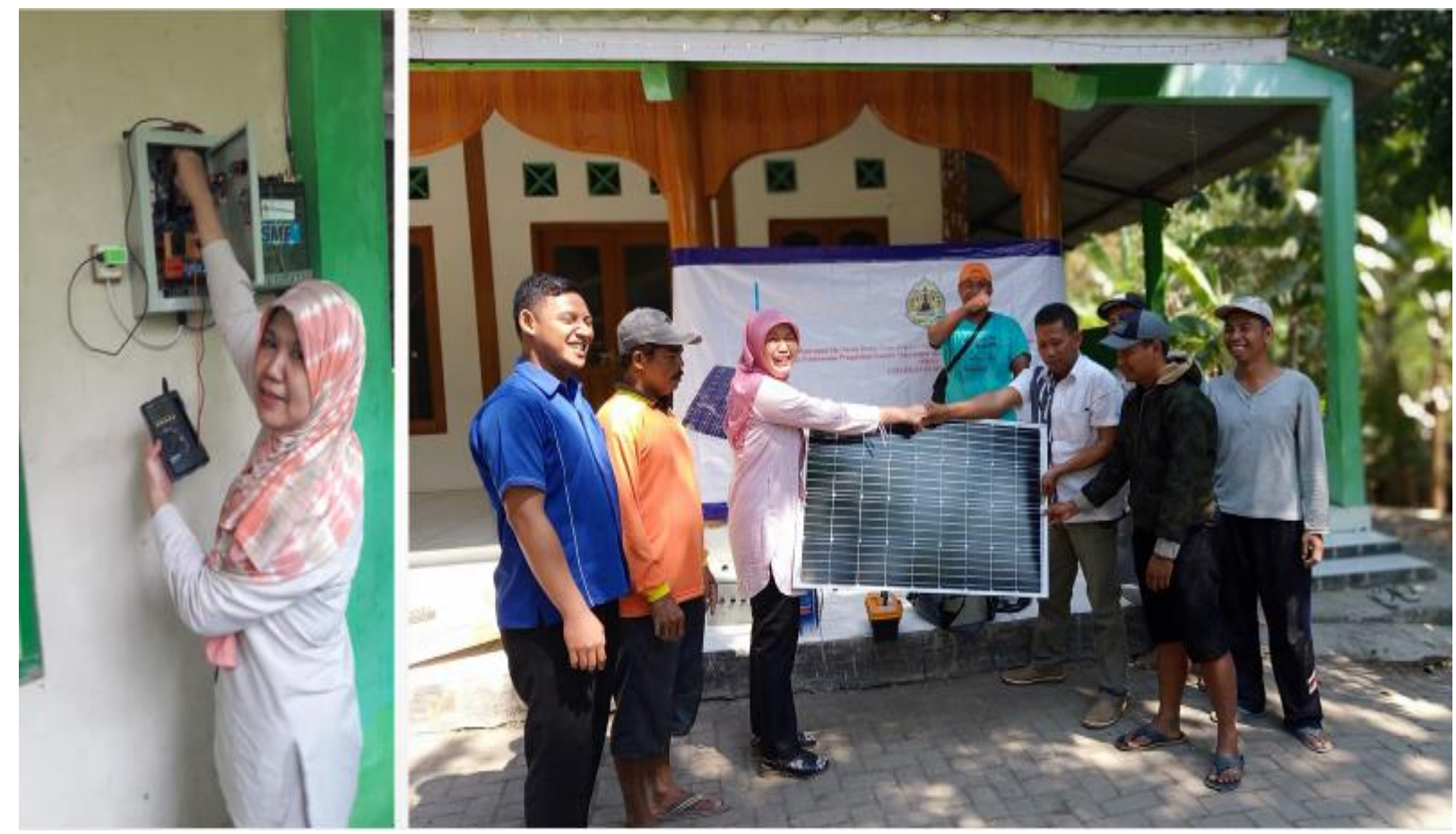

Gambar 5. Pengecekan Kinerja MPPT dan serah terima Peralatan

\section{SIMPULAN}

Beberapa simpulan yang di dapat dari PKM ini adalah ;

1) Masyarakat RT.02/RW.08 Kelurahan Rowosari Kecamatan Tembalang Kota Semarang setuju diterapkanya MPPT pada musholanya dengan indeks 3,5 dalam skala 5.

2) MPPT telah terpasang di mushola RT.02/RW.08 dengan nilai tegangan yang keluar dari panel surya sebesar 12V DC dan tegangan yang keluar dari inverter sebesar 220V AC.

3) Pelaksanaan pelatihan MPPT di RT.02/RW.08 Kelurahan Rowosari Kecamatan Tembalang Kota Semarang dengan 4 tahap pelatihan, mampu meningkatkan pengetahuan tentang MPPT.

4) Masyarakat RT.02/RW.08 Kelurahan Rowosari Kecamatan Tembalang Kota Semarang sangat antusias mengikuti pelatihan MPPT.

\section{Saran}

Pemakaian MPPT untuk menghasilkan energi listrik untuk kebutuhan rumah tangga di terapkan di RT.02/RW.08 Kelurahan Rowosari Kecamatan Tembalang Kota Semarang.

\section{UCAPAN TERIMAKASIH}

Tim pelaksana PKM mengucapkan terima kasih kepada :

- DRPM Kementrian Riset dan Perguruan Tinggi atas pendanaan pelaksanaan PKM ini.

- Universitas Semarang yang telah mendukung penuh pelaksanaan PKM ini. 


\section{REFERENSI}

Harmini, Titik Nurhayati,2017, "ANALISA PERANCANGAN SISTEM POMPA AIR SOLAR PHOTOVOLTAIC DI DESA RAMBAT, GROBOGAN", SENENDO,Yogyakarta

Buku Panduan Pelaksanaan Penelitian dan Pengabdian Kepada Masyarakat di Perguruan Tinggi Edisi XII,Tahun 2018, RISTEKDIKTI, Jakarta

Monografi Kelurahan Rowosari, Oktober 2018

Titik N, 2014, "Aplikasi MPPT (Maximum Power Point Tracker) Pada Sistem Pompa Air SPV (Solar Photovolic)", Jurnal Pengembangan Rekayasa Dan Teknologi | Volume: 14 | Nomor : 2 | ISSN : $1410-9840$ 